\title{
AJUSTAMENTO OSMÓTICO EM MUDAS DE JATOBÁ SUBMETIDAS À SALINIDADE EM MEIO HIDROPÔNICO'
}

Hugo Henrique Costa do Nascimento ${ }^{2}$, Cibele Alves dos Santos ${ }^{3}$, Clarissa Soares Freire ${ }^{4}$, Marcelle Almeida da Silva ${ }^{5}$ e Rejane Jurema Mansur Custódio Nogueira ${ }^{6}$

\begin{abstract}
RESUMO - Em ambientes naturais, a salinidade representa grande empecilho ao desenvolvimento dos vegetais. Visando à melhor compreensão dos efeitos que ela provoca na fisiologia de espécies arbóreas nativas, este trabalho objetivou avaliar o comportamento fisiológico de mudas de jatobá (Hymenaea courbaril L.) submetidas à salinidade em meio hidropônico. Portanto, um experimento foi realizado em casa de vegetação do Laboratório de Fisiologia Vegetal da Universidade Federal Rural de Pernambuco, adotando-se um delineamento experimental inteiramente casualizado em arranjo fatorial 3 x 2, composto por três tratamentos salinos: Controle (solução nutritiva sem adição de $\mathrm{NaCl}$ ), Estresse moderado (adição de $50 \mathrm{mM}$ de $\mathrm{NaCl}$ ) e Estresse severo (adição de $100 \mathrm{mM}$ de $\mathrm{NaCl}$ ) e duas épocas de avaliação ( $1^{\mathrm{a}}$ época: constatação do fechamento estomático; e $2^{\mathrm{a}}$ época: após a verificação da abertura estomática das plantas submetidas à salinidade), com 20 repetições em cada tratamento. Durante o estudo, foram verificadas as trocas gasosas, as relações hídricas, os teores de pigmentos fotossintéticos e o acúmulo de solutos orgânicos e inorgânicos. Ao final do experimento, observou-se que as mudas de jatobá se ajustaram osmoticamente após a indução do estresse severo, uma vez que acumularam solutos orgânicos que promoveram a elevação da turgescência foliar, resultando na estabilização das trocas gasosas, mesmo após a submissão ao estresse severo.
\end{abstract}

Palavras-chave: Estresse salino; Hymenaea courbaril L.; Osmorregulação.

\section{OSMOTIC ADJUSTMENT IN JATOBÁ SEEDLINGS SUBJECTED TO SALINITY IN HYDROPONIC MEDIUM}

\begin{abstract}
In natural environments, salinity is a major impediment to the development of plants. Aiming at a better understanding of the effects it causes in the physiology of native tree species, the present study aimed to evaluate the physiological behavior of jatobá (Hymenaea courbaril L.) seedlings subjected to salinity in hydroponics. Therefore, an experiment was conducted in a greenhouse of the Laboratory of Plant Physiology of the Universidade Federal Rural de Pernambuco, adopting an experimental design completely randomized in a $3 \times 2$ factorial arrangement consisting of three saline treatments: Control (nutrient solution without addition of $\mathrm{NaCl}$ ), moderate stress (addition of $50 \mathrm{mM} \mathrm{NaCl}$ ) and severe stress (addition of $100 \mathrm{mM} \mathrm{NaCl}$ ) and two evaluation periods (1st time evaluation: Finding the stomatal closure; 2 nd time evaluation: After verification of stomatal opening of plants subjected to salinity.), with 20 repetitions for each treatment. During the study gas exchange, water relations, photosynthetic pigments content and accumulation of organic and
\end{abstract}

\footnotetext{
${ }^{1}$ Recebido em 12.07.2013 aceito para publicação em 02.06.2015.

${ }^{2}$ Universidade Federal de Alagoas, Centro de Ciências Agrárias, Rio Largo, Alagoas - Brasil. E-mail: <hugohcnascimento@gmail.com>.

${ }^{3}$ Universidade Federal Rural de Pernambuco, Programa de Pós-Graduação em Ciências Florestais, Recife, Pernambuco - Brasil. E-mail: <belinhaads@hotmail.com>.

${ }^{4}$ Universidade Federal Rural de Pernambuco, Programa de Pós-Graduação em Produção Vegetal, Serra Talhada, Pernambuco - Brasil.E-mail: <clarissa.sfreire@gmail.com>.

${ }^{5}$ Universidade Federal do Vale do São Francisco, Departamento de Biologia, Petrolina, Pernambuco - Brasil.E-mail: <cellyalmeida@hotmail.com>.

${ }^{6}$ Universidade Federal Rural de Pernambuco, Departamento de Biologia, Recife, PE - Brasil. E-mail: <rjmansur1@gmail.com>.
}

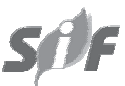

Revista Árvore, Viçosa-MG, v.39, n.4, p.641-653, 2015 http://dx.doi.org/10.1590/0100-67622015000400006 
inorganics solutes were checked. At the end of the experiment it was observed that the seedlings of jatobá adjusted osmotically after induction of severe stress, since they accumulated organic solutes that promoted the elevation of leaf turgor, resulting in stabilization of gas exchange, even after submission to severe stress.

Keywords: Salt stress; Hymenaea courbaril L.; Osmoregulation.

\section{INTRODUÇÃO}

Por definição, salinidade é o termo empregado para indicar o processo de acúmulo de sais solúveis na camada superficial do solo ou no ambiente radicular, onde as plantas estão crescendo (RIBEIRO, 2010) e, em sua grande maioria, em concentrações prejudiciais ao desenvolvimento dos vegetais ali presentes (RAHDARI; HOSEINI, 2011).

Estudos realizados pela Food and Agriculture Organization of the United Nations (FAO) estimam que aproximadamente $6 \%$ (800 milhões de ha) do território mundial é afetado pela salinização dos solos (HOLANDA et al., 2010). Já para o Brasil não se sabe ao certo qual a extensão de áreas afetadas pela salinidade (OLIVEIRA et al., 2010); estima-se, porém, que $25 \%$ das áreas irrigadas enfrentam dificuldades relativas à salinização. Silva et al. (2008) afirmaram que, na maioria dessas áreas, ela ocorre de maneira natural por influência dos sais contidos nas rochas matrizes e em suas reações.

Em geral, a salinidade pode afetar os vegetais de duas formas principais: ocasionando rápida reação à diminuição do potencial osmótico, com consequente redução da condutividade hidráulica do sistema soloplanta (efeito osmótico) (MUNNS; TESTER, 2008) e por uma resposta mais lenta ao acúmulo de sais (efeito iônico ou tóxico) (TAIZ; ZEIGER, 2013). Segundo Chaves et al. (2009), as primeiras respostas osmóticas de uma planta à salinidade são as alterações nas relações hídricas (seca fisiológica), que promovem a diminuição do potencial hídrico foliar ( $\left.\Psi_{\mathrm{W}}\right)$, influenciando diretamente a turgescência celular. Com o comprometimento da manutenção do status hídrico celular, as trocas gasosas são restringidas (parcial ou totalmente), limitando os processos fotossintéticos e transpiracionais (ESTEVES; SUZUKI, 2008). Essas reduções ocasionam prejuízos significativos no desenvolvimento do vegetal (AMORIM et al., 2010).

Além dos efeitos osmóticos, parte da sensibilidade à salinidade está relacionada ao efeito tóxico da acumulação de íons específicos, principalmente o $\mathrm{Cl}^{-}$ e o $\mathrm{Na}^{+}$. Tais efeitos podem ser diretos, quando o vegetal é sensível ao excesso desses íons; ou indiretos, quando a presença do íon prejudica a realização de alguma reação essencial à sobrevivência do vegetal (MUNNS; TESTER, 2008; RAHDARI; HOSEINI, 2011).

Outra resposta das plantas à salinidade é o acúmulo de substâncias como carboidratos, proteínas e aminoácidos no interior da célula. Entre essas, destacase a prolina, por ser um metabólito relacionado ao estresse, auxiliando na osmorregulação e favorecendo o aumento da tolerância de certos níveis de estresses hídrico e salino, o que já foi comprovado em diversas plantas (TURKAN, 2011; TAIZ; ZEIGER, 2013).

Entre as espécies florestais nativas do Brasil, o jatobá (Hymenaea courbaril L.) tem despertado o interesse de pesquisadores, por apresentar ampla distribuição geográfica (Piauí até o Norte do Paraná) e ocorrer em ecossistemas onde a maioria dos vegetais não consegue se desenvolver satisfatoriamente (MATHEUS et al., 2011; NASCIMENTO et al., 2011).

Embora o jatobá se apresente como espécie promissora para programas de reflorestamento e, ou, recuperação de áreas degradadas, o conhecimento sobre as respostas fisiológicas dessa árvore ante a salinidade ainda é incipiente. Visando contribuir para o conhecimento dessa espécie em relação ao seu comportamento e ajustes fisiológicos, o objetivo deste trabalho é avaliar os efeitos da salinidade sobre as trocas gasosas, relações hídricas, teores de pigmentos fotossintéticos e acúmulo de solutos orgânicos e inorgânicos em mudas de jatobá.

\section{MATERIAL E MÉTODOS}

O experimento foi desenvolvido em casa de vegetação do Laboratório de Fisiologia Vegetal da Universidade Federal Rural de Pernambuco, Recife, PE (49,2 ${ }^{\circ} 00^{\prime} 8$ ", S e 59,98 56'34' O). Utilizaram-se mudas, propagadas sexuadamente, a partir de sementes coletadas no Município de Garanhuns, agreste pernambucano e área de ocorrência da espécie. As sementes foram submetidas à superação de dormência realizada por imersão em

Revista Árvore, Viçosa-MG, v.39, n.4, p.641-653, 2015 
ácido sulfúrico (98\%) durante 35 min (MELO et al., 2004). Depois da lavagem, as sementes foram semeadas em areia lavada e, no $30^{\circ}$ dia após a semeadura, as plântulas foram transplantadas para recipientes contendo 35 L de solução nutritiva de Hoagland e Arnon (1950) a $1 / 2$ de força iônica. Após o transplantio, elas foram aclimatadas por 30 dias antes da aplicação dos tratamentos em um sistema hidropônico com aeração artificial, utilizando-se bombas de aquário, em que a solução nutritiva foi substituída quinzenalmente até o final do experimento.

O delineamento adotado foi inteiramente casualizado em arranjo fatorial $3 \times 2$, composto por três tratamentos salinos: Controle (solução nutritiva sem adição de $\mathrm{NaCl}$ ), Estresse moderado (adição de $50 \mathrm{mM}$ de $\mathrm{NaCl}$ ) e Estresse severo (adição de $100 \mathrm{mM}$ de $\mathrm{NaCl}$ ) e duas épocas de avaliação ( 1 a época de avaliação - na ocasião do fechamento estomático em razão da salinidade; $2^{\mathrm{a}}$ época de avaliação - quando se constatou a abertura estomática das plantas submetidas ao tratamento severo, após elas serem transferidas para solução nutritiva sem adição de $\mathrm{NaCl}$ ). Cada tratamento foi composto por 20 repetições, em que uma planta correspondia a uma unidade experimental.

Após o período de aclimatação, teve início a diferenciação dos tratamentos salinos, em que se adicionou o $\mathrm{NaCl}$ em quantidades adequadas para se obterem os tratamentos propostos. Esse procedimento foi feito durante quatro dias, adicionando-se $25 \mathrm{mM}$ de $\mathrm{NaCl}$ por dia até resultar nos tratamentos 50 e $100 \mathrm{mM}$. Semanalmente, foi realizado o monitoramento da Condutividade Elétrica (CE) utilizando um condutivímetro digital da marca Soil Control, constatando-se que as CE das soluções de 50 e $100 \mathrm{mM}$ eram de 5,5 e $8,5 \mathrm{dS} \mathrm{m}^{-1}$, respectivamente.

No intuito de determinar o horário de maior abertura estomática, fez-se necessária a realização de mensurações diárias das trocas gasosas, realizadas das 6 h às 18 $\mathrm{h}$ em intervalos de $2 \mathrm{~h}$, durante dois dias consecutivos. As medições foram realizadas na folha +2 (segunda folha completamente expandida após a gema apical), utilizando um analisador portátil de $\mathrm{CO}_{2}$ a infravermelho (IRGA), ADC, modelo LcPro+. De maneira geral, observou-se que os valores mais elevados de fotossíntese $\left(13,77 \mu \mathrm{mol} \mathrm{CO} \mathrm{CO}_{2} \cdot \mathrm{m}^{-2} \cdot \mathrm{s}^{-1}\right)$ foram registrados entre as $10 \mathrm{~h}$ e $12 \mathrm{~h}$. Após a definição do intervalo de maior atividade estomática, diariamente foram avaliadas a fotossíntese (A), transpiração (E), condutância estomática (gs) e concentração interna de $\mathrm{CO}_{2}(\mathrm{Ci})$, sempre nos intervalos das 10 às $12 \mathrm{~h}$. De posse dos valores de $\mathrm{A}$ e E, foi calculada a eficiência do uso da água (A/E), segundo Osmond et al. (1980). O período experimental foi de 106 dias, sendo 30 dias para a germinação, 30 dias para a aclimatação e 46 dias de monitoramento estomático e avaliações do comportamento fisiológico das plantas submetidas à salinidade.

Após a constatação do fechamento estomático em função da alta concentração de $\mathrm{NaCl}$ presente nas soluções de 50 e 100 mM, 10 repetições de cada tratamento foram submetidas às avaliações dos parâmetros fisiológicos, em que foram avaliadas as relações hídricas, a quantificação dos pigmentos fotossintéticos e os teores de solutos orgânicos e inorgânicos em folhas e raízes ( $1^{\text {a }}$ época de avaliação). O restante das plantas dos tratamentos 50 e 100 mM (10 repetições de cada tratamento) foi submetido à lavagem das raízes para a retirada da solução salina e, posteriormente, mantidas nas mesmas condições das plantas do tratamentocontrole $\left(1 \mathrm{dS} \mathrm{m}^{-1}\right)$ até ser observada a reabertura dos estômatos. No momento em que trocas gasosas das plantas anteriormente cultivadas a 50 e $100 \mathrm{mM}$ se equipararam aos valores das plantas do tratamentocontrole, os parâmetros fisiológicos foram novamente avaliados ( $2^{\mathrm{a}}$ época de avaliação).

Diariamente, foram tomadas medidas da temperatura do $\operatorname{ar}\left(\mathrm{T}^{\circ} \mathrm{C}\right)$ e umidade relativa do $\operatorname{ar}(\mathrm{UR} \%)$ no interior da casa de vegetação, com o auxílio de um termohigrômetro, e calculado o déficit de pressão de vapor d'água (DPV), segundo Vianello e Alves (1991). O monitoramento revelou que a temperatura do ar (Tar) média foi de $31,6^{\circ} \mathrm{C}$, variando de 25,8 a $41,9^{\circ} \mathrm{C}$, sendo mais elevadas nos horários de maior intensidade luminosa. A UR média foi de 54,9\%, variando de 32 a $82 \%$. Já o DPV médio entre o interior da folha e o ar foi de 2,45 $\mathrm{kPa}$, variando de 0,72 a 4,12 $\mathrm{kPa}$, em que os valores mais elevados foram observados nos instantes em que a Tar apresentou os valores mais elevados e a UR, seus menores valores.

Para determinação das relações hídricas, foram estudados o potencial hídrico foliar ( $\left.\Psi_{W}\right)$ e o Teor Relativo de Água (TRA). As avaliações ocorreram ao longo do dia, com intervalos de $6 \mathrm{~h}$, da $0 \mathrm{~h}$ às $18 \mathrm{~h}$. A determinação do $\Psi_{\mathrm{W}}$ foi realizada em folíolos completamente expandidos situados no terço médio superior da planta. Após serem destacados, os folíolos

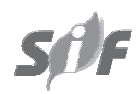

Revista Árvore, Viçosa-MG, v.39, n.4, p.641-653, 2015 
foram rapidamente envolvidos em filme plástico e armazenados em recipiente sob refrigeração para evitar a perda de água. Logo em seguida, procederam-se às determinações utilizando uma câmara de pressão de Scholander modelo 3035 (SCHOLANDER et al., 1965). As avaliações do TRA procederam-se nos folíolos vizinhos aos folíolos utilizados na determinação do $\Psi$ w, seguindo o método descrito por Weatherley (1950).

A quantificação dos teores de pigmentos fotossintéticos (clorofilas $a, b$, Total, carotenoides e relação $\mathrm{Cl} a / \mathrm{Cl} b$ ) foi realizada nas mesmas folhas utilizadas para a avaliação das trocas gasosas. As folhas foram cortadas e introduzidas em tubos de ensaio contendo álcool etílico 95\%, avaliando-se os teores de pigmentos após $48 \mathrm{~h}$. As leituras dos teores de clorofilas $a, b$, bem como dos carotenoides, foram realizadas em espectrofotômetro (Biospectro, modelo SP-220), segundo o método descrito por Lichtenthaler e Buschmann (2001); posteriormente, a comprovação do fechamento estomático e, após, a reirrigação e o restabelecimento das trocas gasosas.

Para a quantificação dos solutos orgânicos, foi coletado $1 \mathrm{~g}$ de folhas e raízes, as quais foram etiquetadas, envoltas em papel-alumínio e acondicionadas em nitrogênio líquido. Após o preparo dos extratos, foram quantificados os carboidratos livres totais, determinados pelo método de fenol-ácido sulfúrico (DUBOIS et al., 1956), empregando-se a D-(+)-glucose como padrão. Quanto aos teores de proteína, estes foram quantificados, aplicando-se a metodologia da ligação ao corante coomassie brilliant blue (BRADFORD, 1976), utilizando albumina sérica bovina como padrão. Já para os aminoácidos se utilizou o método da ninidrina (YEMM; COCKING, 1955), tendo a glicina como padrão. Por fỉm, a concentração de prolina livre foi determinada, aplicando-se a metodologia da ninidrina e ácido fosfórico proposta por Bates (1973), tendo a prolina como padrão. Além da avaliação dos solutos orgânicos, foi realizada a determinação de $\mathrm{Na}^{+}, \mathrm{Cl}^{-}$e $\mathrm{K}^{+}$a partir da biomassa seca das folhas, caules e raízes moídos em moinho de facas tipo Willey. Para a quantificação dos teores de $\mathrm{Na}^{+} \mathrm{e} \mathrm{K}^{+}$, a matéria seca moída foi submetida à digestão nitroperclórica e, posteriormente, realizadas as análises por fotometria de chama de emissão, seguindo o proposto por Malavolta et al. (1989). Para a quantificação dos teores de $\mathrm{Cl}$, foi adotado o método de Mohr, utilizando titulometria com nitrato de prata (MALAVOLTA et al., 1989).

Revista Árvore, Viçosa-MG, v.39, n.4, p.641-653, 2015
Os dados foram submetidos à análise de variância para detectar possíveis efeitos dos tratamentos sobre as variáveis analisadas, utilizando-se o software ASSISTAT versão 7.6 beta, e as médias foram comparadas entre si, pelo teste de Tukey $(\mathrm{P}<0,05)$.

\section{RESULTADO}

De maneira geral, todas as variáveis estudadas foram significativamente $(\mathrm{P}>0,01)$ alteradas pelos efeitos da salinidade. A interpretação das variáveis revelou que a fotossíntese (Figura 1A), a transpiração (Figura 1B) e a condutância estomática (Figura 1C) apresentaram comportamento similar. Isto é, após a imposição da salinidade, foram observadas as primeiras alterações no $3^{\circ}$ e $5^{\circ}$ dias após a diferenciação (DAD) dos tratamentos salinos, respectivamente, mantendo-se até o $45^{\circ} \mathrm{DAD}$, momento em que se constatou similaridade na fixação de $\mathrm{CO}_{2}$ entre os tratamentos. No entanto, a verificação do fechamento estomático ( $\mathrm{gs}=0 \mathrm{~mol} \mathrm{H} \mathrm{H}_{2} \mathrm{O} \cdot \mathrm{m}^{-2} \cdot \mathrm{s}^{-1}$ ) das plantas do tratamento $100 \mathrm{mM}$ de $\mathrm{NaCl}$ ocorreu após 25 dias de exposição à salinidade. Em contrapartida, as plantas do tratamento $50 \mathrm{mM}$, apesar de apresentar reduções, não fecharam seus estômatos durante o período avaliado, evidenciando taxas fotossintéticas similares ao tratamento-controle no $40^{\circ}, 44^{\circ}$ e $45^{\circ} \mathrm{DAD}$.

Outro fato que merece ser ressaltado ocorreu no $7^{\circ}, 8^{\circ} 12^{\circ}$ e $17^{\circ} \mathrm{DAD}$, quando as plantas do tratamento $100 \mathrm{mM}$ apresentaram sinais de recuperação fotossintética, uma vez que elas apresentaram valores superiores de fotossíntese em relação aos dias anteriores $\left(6^{\circ}, 11^{\circ}\right.$ e $16^{\circ} \mathrm{DAD}$, respectivamente), oscilações também observadas nos outros tratamentos.

$\mathrm{Na}$ avaliação da concentração interna de $\mathrm{CO}_{2}$ (Figura 1D) e da eficiência do uso da água (Figura 1E), notou-se que ambas apresentaram poucas oscilações em razão dos tratamentos salinos; no entanto, entre o $23^{\circ}$ e o $26^{\circ} \mathrm{DAD}$ foram observadas alterações drásticas nessas variáveis, em que a $\mathrm{Ci}$ foi elevada em função do fechamento estomático e da $\mathrm{A} / \mathrm{E}$, restringida pela ausência de fixação de carbono e transpiração.

As determinações das relações hídricas revelaram que o $\Psi \mathrm{W}$ foi afetado pela salinidade, apresentando contrastes estatísticos em função dos tratamentos e horários de avaliação. Na primeira época de avaliação, observou-se que os valores mais elevados de $\Psi_{\mathrm{W}}$ foram verificados nas plantas do tratamento-controle, 


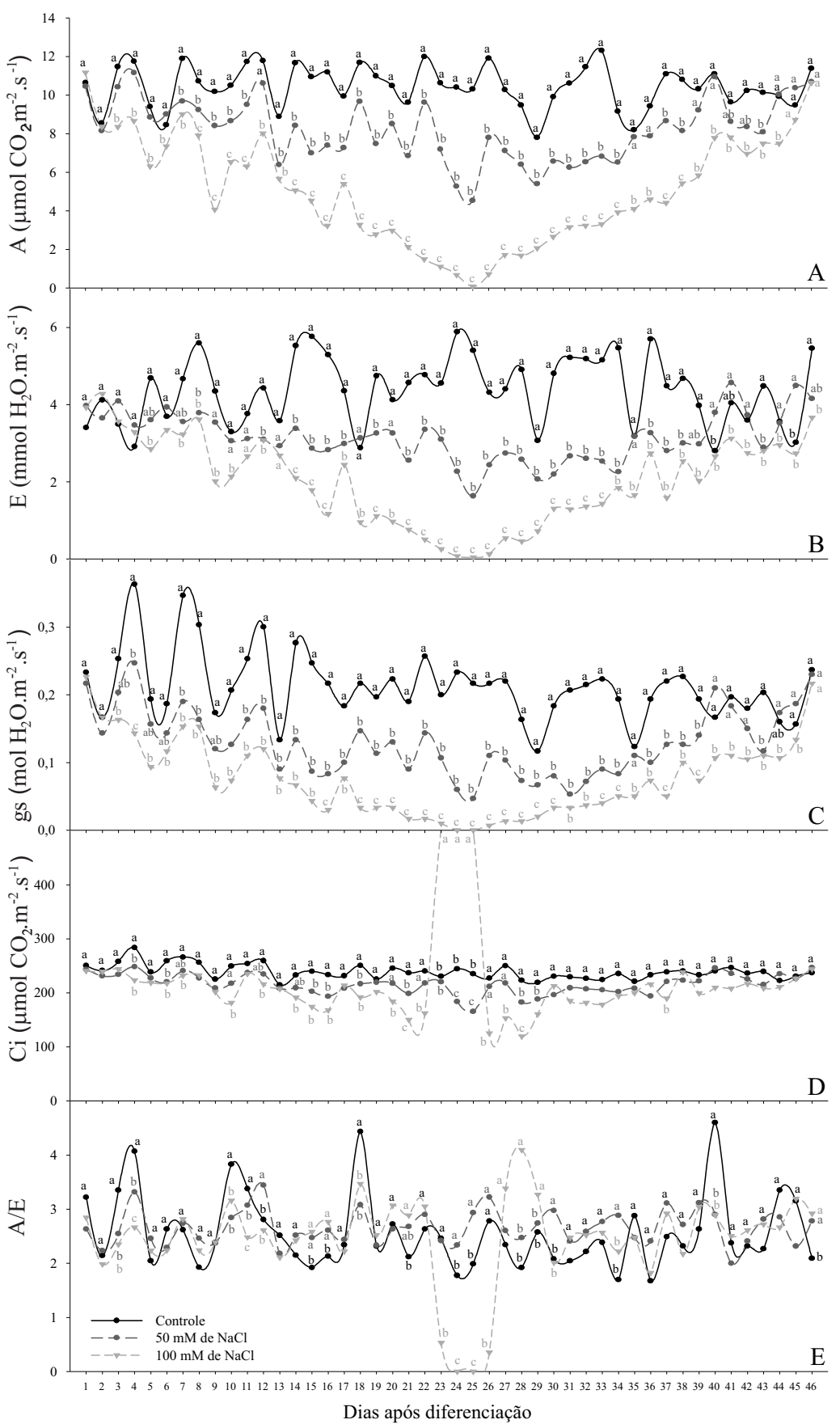

Figura 1 - Fotossíntese (A), transpiração (E), condutância estomática (gs), concentração interna de $\mathrm{CO}_{2}(\mathrm{Ci})$ e eficiência de uso da água (A/E) em mudas de jatobá (Hymenaea courbaril L.) cultivadas em três níveis de salinidade. Letras minúsculas pretas, cinza-escuras e cinza-claras comparam as plantas do tratamento-controle, $50 \mathrm{mM}$ e 100 $\mathrm{mM}$ de $\mathrm{NaCl}$, respectivamente, e letras iguais não diferem entre si, pelo teste de Tukey a $5 \%$.

Figure 1 - Photosynthesis (A), transpiration (E), stomatal conductance (gs), internal $\mathrm{CO}_{2}$ concentration (Ci) and water use efficiency (A/E) in jatobá (Hymenaea courbaril L.) seedlings grown in three salinity levels. Lowercase letters black, dark gray and light gray compare the control plants, $50 \mathrm{mM}$ and $100 \mathrm{mM} \mathrm{NaCl}$, respectively, and same letter do not differ by Tukey test at 5\%. 
independentemente dos horários de avaliação, em que foram evidenciados os maiores contrastes nas horas mais frias do dia (Figura 2A).

Na segunda época de avaliação do $\Psi_{\mathrm{w}}$, notou-se que, após a substituição da solução salina por uma solução nutritiva completa sem a adição de $\mathrm{NaCl}$, as plantas do tratamento $100 \mathrm{mM}$ apresentaram os valores mais estáveis, mesmo às $12 \mathrm{~h}$, diferenciando-se dos demais tratamentos (Figura 2B). Nesse horário, às $12 \mathrm{~h}$, as plantas dos tratamentos-controle e $50 \mathrm{mM}$ apresentaram reduções na ordem de 55,6 e 60\%, respectivamente, para o $\Psi \mathrm{w}$, em comparação com o referido tratamento. Apesar dessas reduções, vale ressaltar que nos demais horários de avaliação os $\Psi_{\mathrm{W}}$ não diferiram entre si.

As avaliações do TRA (Figura 2C) indicaram que, exceto no tratamento de $100 \mathrm{mM}$ avaliado às $12 \mathrm{~h}$, a salinidade não causou reduções na turgescência foliar das plantas de jatobá, na primeira época de avaliação, em que apenas as plantas submetidas ao estresse severo (100 mM) apresentaram reduções na ordem de 12,8\%, em comparação com o tratamento-controle. De forma semelhante ao apresentado nas avaliações do $\Psi \mathrm{W}$, na segunda época de avaliação ( $\left.46^{\circ} \mathrm{DAD}\right)$ foi possível verificar que as plantas do tratamento $100 \mathrm{mM}$ se mostraram mais hidratadas no horário de maior demanda evaporativa, diferenciando-se estatisticamente dos demais tratamentos, os quais tiveram reduções de 15,3 e $12,3 \%$ nos tratamentos-controle e $50 \mathrm{mM}$ de $\mathrm{NaCl}$ (Figura 2D).

Os teores de clorofila $a$ (Figura 3A), $b$ (Figura 3B) e relação $\mathrm{Cl} a / \mathrm{Cl} b$ (Figura $3 \mathrm{E}$ ) não diferiram significativamente entre os tratamentos. No entanto, verificou-se que a salinidade induziu incrementos significativos $(\mathrm{P}<0,01)$ nos teores de clorofila total (para 50 e $100 \mathrm{mM}$, respectivamente) (Figura 3C) e carotenoides (Figura 3D). Esses incrementos foram de 25,25 e 27,60\% para clorofila total e de 26,25 e $28,70 \%$ para 50 e 100 $\mathrm{mM}$, respectivamente, nos carotenoides.

Em relação aos solutos orgânicos, pode-se resumir que, exceto nos carboidratos e aminoácidos das raízes, todos os outros solutos orgânicos avaliados tiveram seus valores elevados em razão do aumento $(\mathrm{P}<0,01)$ da salinidade. Destacando-se os resultados da primeira época de avaliação que, em sua grande maioria, apresentaram os maiores valores no tratamento de 100
$\mathrm{mM}$, nas folhas e menores nas raízes, exceto na prolina, onde foi verificado incremento em seus valores, à medida que a concentração de $\mathrm{NaCl}$ foi aumentada.

Os resultados evidenciaram acréscimo nos teores de carboidrato (2,81x; Figura 4A), proteína (3,9x; Figura 4C), aminoácidos (1,7x Figura 4E) e prolina (2,1x Figura $4 \mathrm{G})$ nas folhas das plantas submetidas a $100 \mathrm{mM}$ de $\mathrm{NaCl}$. Já nas raízes esses incrementos foram da ordem de 1,9x para proteína e 7x para a prolina. Em contrapartida, a salinidade reduziu os carboidratos (2,43\% Figura 4B) e aminoácidos nas raízes (1,4x Figura $4 \mathrm{~F})$.

Avaliando os teores de solutos inorgânicos, observou-se que, como esperado, exceto para o $\mathrm{K}^{+}$, todos os outros solutos apresentaram incrementos significativos $(\mathrm{P}<0,01)$ em razão da salinidade (Figura 5D-F). Esse comportamento foi mais evidente nos teores de $\mathrm{Cl}^{-}$, em que foram verificados aumentos da ordem de 60x e 29x nas folhas (Figura 5G); 36x e $17 x$ nos caules (Figura $5 \mathrm{H}$ ) e $28 \mathrm{x}$ e $16 \mathrm{x}$ nas raízes (Figura 5I) das plantas submetidas a estresses severo e moderado, respectivamente. Após a lavagem das raízes, foi observado que a concentração de $\mathrm{Cl}^{-}$não diminuiu significativamente em relação à época de avaliação anterior, o que era esperado, uma vez que não há relatos de eliminação natural de sal pelo jatobá, havendo efeito cumulativo com o passar do tempo.

$\mathrm{Na}$ avaliação do $\mathrm{Na}^{+}$, foram observados acúmulos de $31 \mathrm{x}$ e $43 \mathrm{x}$ nos tratamentos $50 \mathrm{mM}$ e $100 \mathrm{mM}$, respectivamente, em relação às raízes do tratamentocontrole (Figura 5C). Já para o $\mathrm{K}^{+}$, independentemente do órgão avaliado ou da época de avaliação, os maiores valores foram verificados no tratamento-controle. Outro fato que merece ser destacado é que, após a lavagem das raízes, verificou-se que os teores de $\mathrm{Na}^{+}$foram reduzidos após o alívio do estresse.

\section{DISCUSSÃO}

Após a lavagem das raízes $\left(25^{\circ} \mathrm{DAD}\right)$, observou-se discreta recuperação das trocas gasosas evidenciada pelo aumento gradativo das taxas fotossintéticas em ambos os tratamentos salinos. Larcher (2004) classificou esse comportamento como um estágio inicial da rustificação e pode ser interpretado como tentativa de recuperação das trocas gasosas, a depender do tipo de agente estressor e do DPV. 


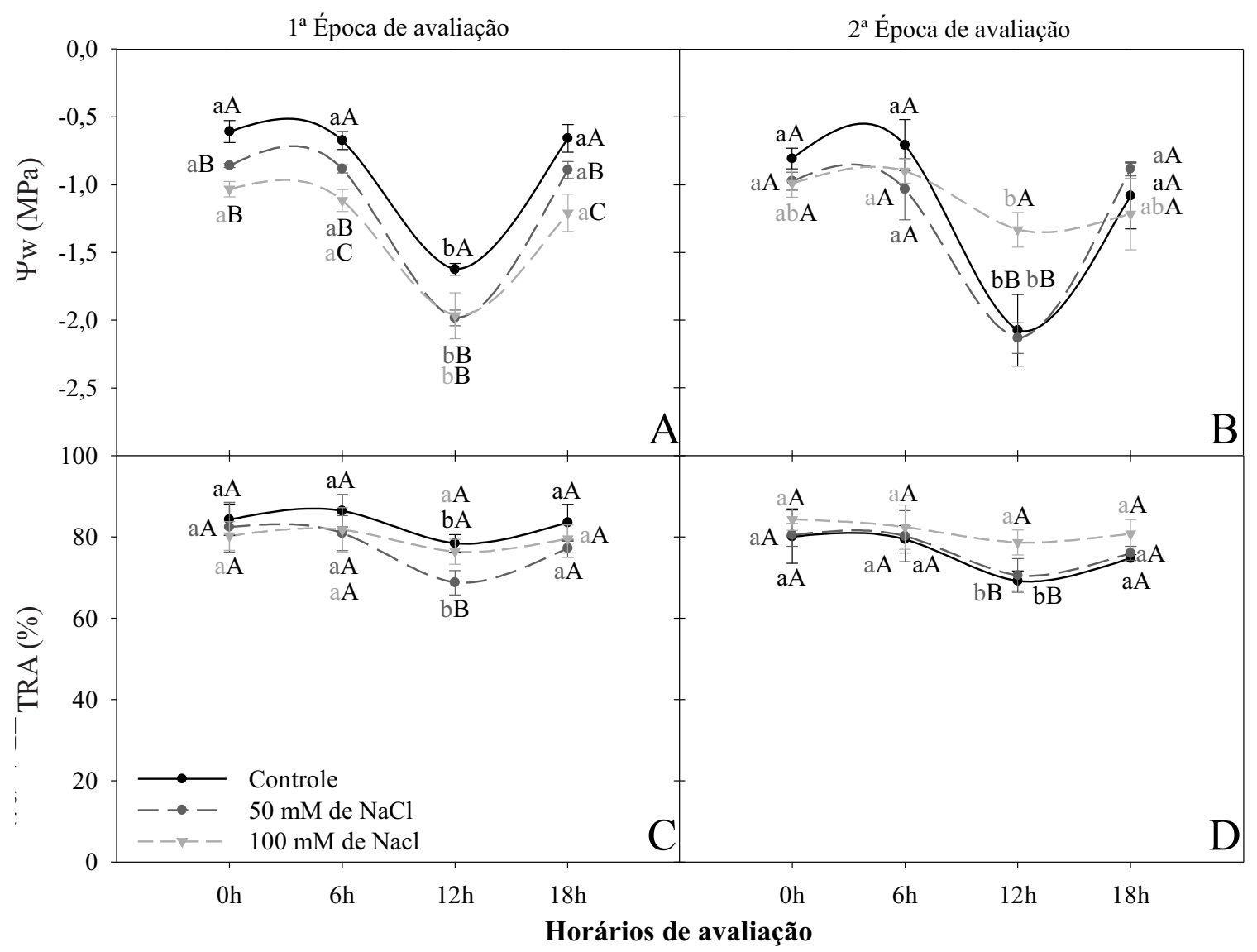

Figura 2 - Potencial hídrico foliar ( $\left.\Psi_{\mathrm{w}}\right)$ e teor relativo de água (TRA) em mudas de jatobá (Hymenaea courbaril L.) cultivadas em três níveis de salinidade, em duas épocas de avaliação. Letras maiúsculas comparam os níveis de salinidade em cada horário de avaliação, e letras minúsculas pretas, cinza-escuras e cinza-claras comparam as plantas do tratamento-controle, $50 \mathrm{mM}$ e $100 \mathrm{mM}$ de NaCl , respectivamente. Letras iguais não diferem entre si, pelo teste

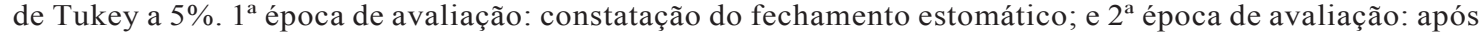
a verificação da abertura estomática das plantas submetidas à salinidade.

Figure 2 - Leaf water potential ( $\Psi w$ ) and relative water content (RWC) in jatobá (Hymenaea courbaril L.) seedlings grown in three salinity levels in two evaluation periods. Capital letters compare the salinity levels in each period of the day and lowercase letters black, dark gray and light gray compare the control plants, $50 \mathrm{mM}$ and $100 \mathrm{mM}$ $\mathrm{NaCl}$, respectively. Same letter do not differ by Tukey test at 5\%. 1st time evaluation: finding the stomatal closure; 2nd time evaluation: after verification of stomatal opening of plants subjected to salinity.

Os valores de $\Psi$ w obtidos levam a crer que a salinidade auxilia nos processos de reidratação das plantas, uma vez o acúmulo de $\mathrm{NaCl}$ proveniente da elevada carga iônica dos solutos no interior da planta faz que nas horas mais frias do dia sejam verificadas a reidratação máxima das mudas submetidas à salinidade. Em muitas situações, essa reidratação tende a equilibrar o $\Psi \mathrm{W}$ ao $\Psi \mathrm{m}$ (potencial mátrico) do substrato em questão (NOBEL, 1999; PIMENTEL, 2004)
Ainda sobre a determinação das relações hídricas deste estudo, Silva et al. (2008), trabalhando com mudas de umbuzeiro submetidas à salinidade, concluíram que essa planta mantém o $\Psi_{\mathrm{W}}$ elevado nas horas mais frias do dia (antemanhã). Contudo, esses autores atribuíram essa elevação do $\Psi \mathrm{w}$, mesmo em condições severas de salinidade, à capacidade que a espécie possui de estocar solutos orgânicos nos xilopódios, estruturas localizadas nas raízes que auxiliam a espécie em situações de estresse hídrico e, ou, salino.

Revista Árvore, Viçosa-MG, v.39, n.4, p.641-653, 2015 


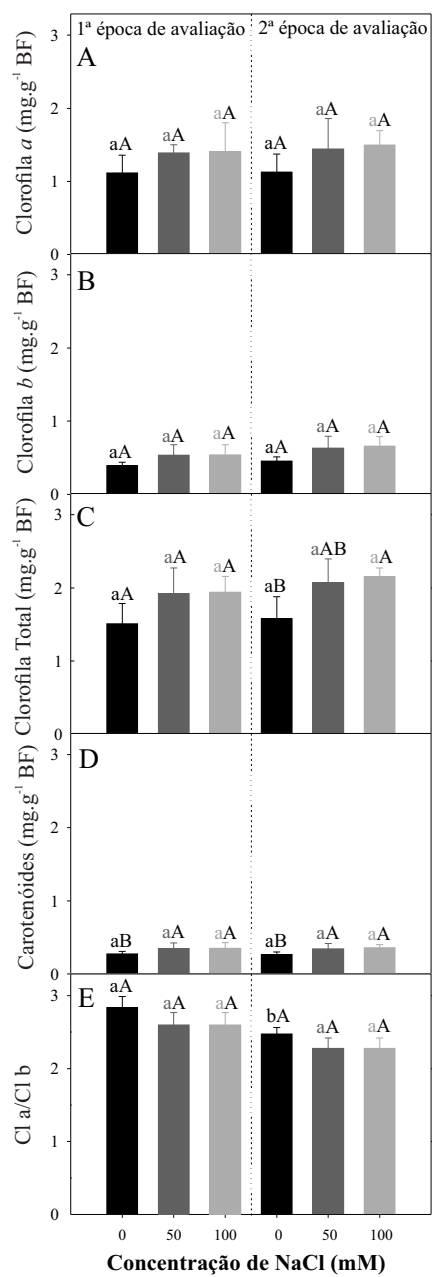

Figura 3-Quantificação dos teores de pigmentos fotossintéticos em mudas de jatobá(Hymenaea courbaril L.) cultivadas em três níveis de salinidade, em duasépocas de avaliação. Letras maiúsculas comparam os níveis de salinidade em cada época de avaliação, e letras minúsculas pretas, cinza-escuras e cinza-claras comparam as plantas do tratamento-controle, $50 \mathrm{mM} \mathrm{e} 100 \mathrm{mM}$ de $\mathrm{NaCl}$, respectivamente. Letras iguais não diferem entre si,

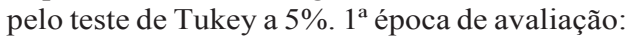
constatação do fechamento estomático; e $2^{\mathrm{a}}$ época de avaliação: após a verificação da abertura estomática das plantas submetidas à salinidade.

Figure 3-Quantification of photosynthetic pigments content in jatobá (Hymenaea courbaril L.) seedlings grown in three salinity levels in two evaluation times. Capital letters compare the saline levels in each timing and lowercase letters black, dark gray and light gray compare the control plants, $50 \mathrm{mM}$ and $100 \mathrm{mM}$ $\mathrm{NaCl}$, respectively. Same letter do not differ by Tukey test at 5\%. 1st time evaluation: finding the stomatal closure; 2nd time evaluation: after verification of stomatal opening of plants subjected to salinity.
Quanto aos pigmentos fotossintéticos, o acúmulo de carotenoides nas plantas submetidas à salinidade também foi verificado por Pinheiro et al. (2006), trabalhando com mamona (Ricinus communis L.), em que foi observado incremento nos teores de carotenoides e clorofilas totais quando as plantas foram submetidas ao estresse por $\mathrm{NaCl}$. Sobre tal comportamento, Esteves e Suzuki (2008) afirmaram que esses teores são pigmentos relacionados à proteção celular contra danos fotoxidativos e, de acordo com Tanaka e Tanaka (2006), eles são componentes das membranas dos tilacoides, presentes nos cloroplastos, e têm a função de dissipar, na forma de calor e, ou, fluorescência, a energia dos fótons de luz capturados pelos pigmentos. Dessa forma, o aumento desses pigmentos pode estar relacionado à recuperação gradativa das trocas gasosas após a retirada do sal.

Ainda sobre o tema, Akça e Samsunlu (2012) afirmaram que as mudanças no conteúdo de clorofila e carotenoides podem ser indicadas como importantes fatores para o crescimento e tolerância das plantas a ambientes diversos. Já para os solutos orgânicos a diminuição no teor de açúcares solúveis nas raízes do tratamento $100 \mathrm{mM}$ de $\mathrm{NaCl}$ pode indicar que esteja ocorrendo o consumo imediato desses para a manutenção da sobrevivência das plantas, fato sugerido por Liu et al. (2011). Em contrapartida, Parida et al. (2005) afirmaram que o aumento do teor de carboidratos tem papel fundamental na regulação osmótica e manutenção dos níveis de água nas folhas.

Em relação às proteínas, estudos relacionando a participação dessas nos processos de proteção contra a desidratação revelaram que algumas plantas acumulam proteínas no apoplasto após a exposição a agentes estressores, como a seca e a salinidade (SUBBARAO, 2000). As justificativas para esse acontecimento estão relacionadas com sequestro de íons, proteção das membranas e retenção de água, fatores esses, por sua vez, que atuam diretamente no processo de ajustamento osmótico (ZHU, 2003). E, através dessa estratégia, poderia manter os níveis de água nas folhas, bem como o equilíbrio osmótico das células (LOBATO et al., 2008), fato que pode explicar o aumento no conjunto de proteínas ocorrido neste estudo. Quanto aos aminoácidos livres totais, o incremento verificado ocorreu devido ao aumento na biossíntese desse composto (OLIVEIRA et al., 2010), haja vista que não foram verificadas taxas de degradação de proteínas que justifiquem tal elevação. 


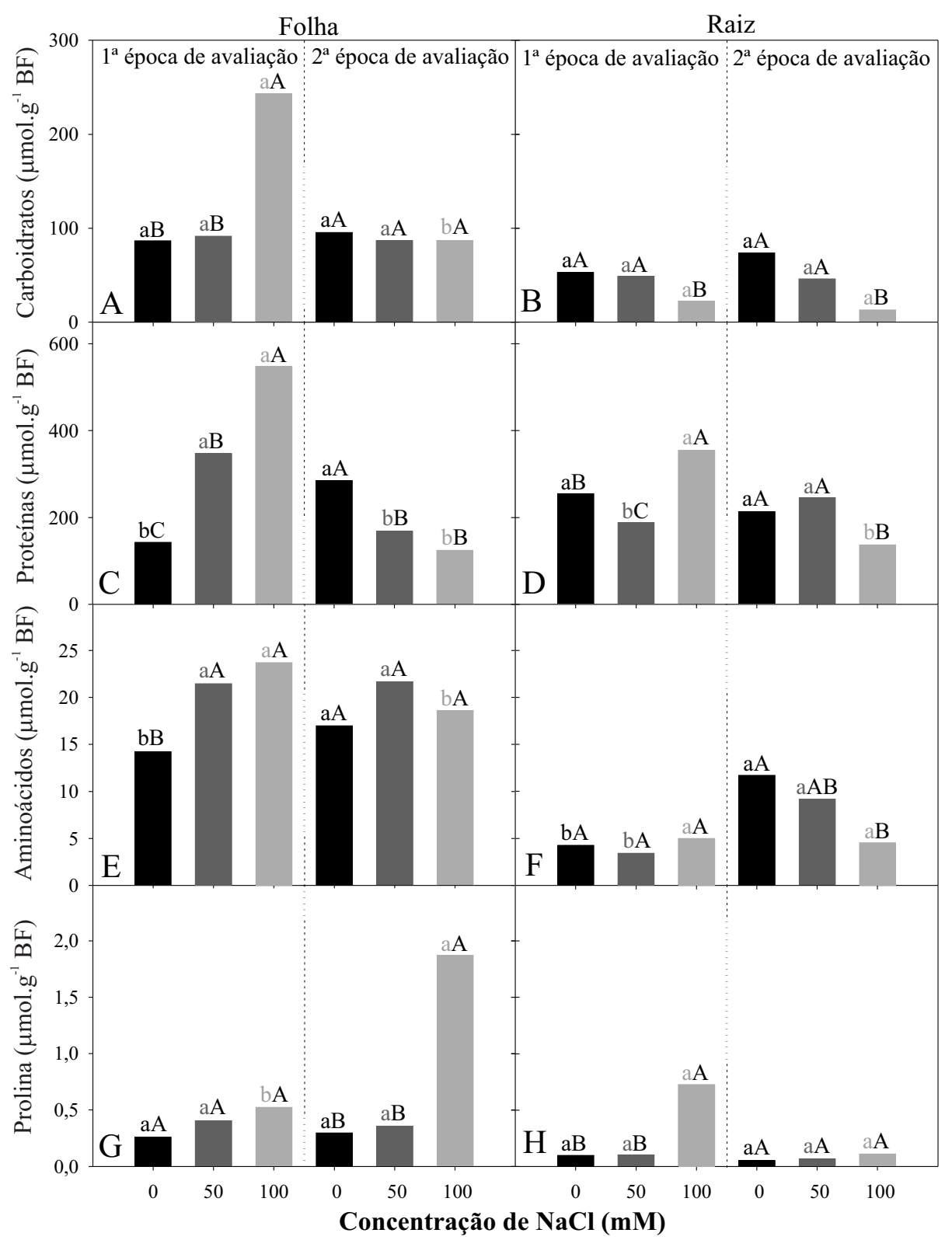

Figura 4-Carboidratos solúveis totais, proteínas solúveis, aminoácidos e prolina livre em folhas (A, C, E e G, respectivamente) e raízes (B, D, F e H, respectivamente) em mudas de jatobá (Hymenaea courbaril L.) cultivadas em três níveis de salinidade, em duas épocas de avaliação. Letras maiúsculas comparam os tratamentos salinos em cada época de avaliação, e letras minúsculas pretas, cinza-escuras e cinza-claras comparam as plantas do tratamentocontrole, $50 \mathrm{mM}$ e $100 \mathrm{mM}$ de $\mathrm{NaCl}$, respectivamente. Letras iguais não diferem entre si, pelo teste de Tukey a $5 \% .1^{\text {a }}$ época de avaliação: constatação do fechamento estomático; e $2^{\mathrm{a}}$ época de avaliação: após a verificação da abertura estomática das plantas submetidas à salinidade.

Figure 4 - Total soluble carbohydrates, soluble proteins, amino acids and free proline in leaves ( $A, C$, E, and $G$, respectively) and roots ( $B, D, F$ and $H$, respectively) in jatobá (Hymenaea courbaril L.) seedlings grown in three salinity levels in two evaluation periods. Capital letters compare the saline treatments in each evaluation timing and lowercase letters black, dark gray and light gray compare the control plants, $50 \mathrm{mM}$ and $100 \mathrm{mM} \mathrm{NaCl}$, respectively. Same letter do not differ by Tukey test at 5\%. 1st time evaluation: finding the stomatal closure; and 2nd time evaluation: after verification of stomatal opening of plants subjected to salinity. 


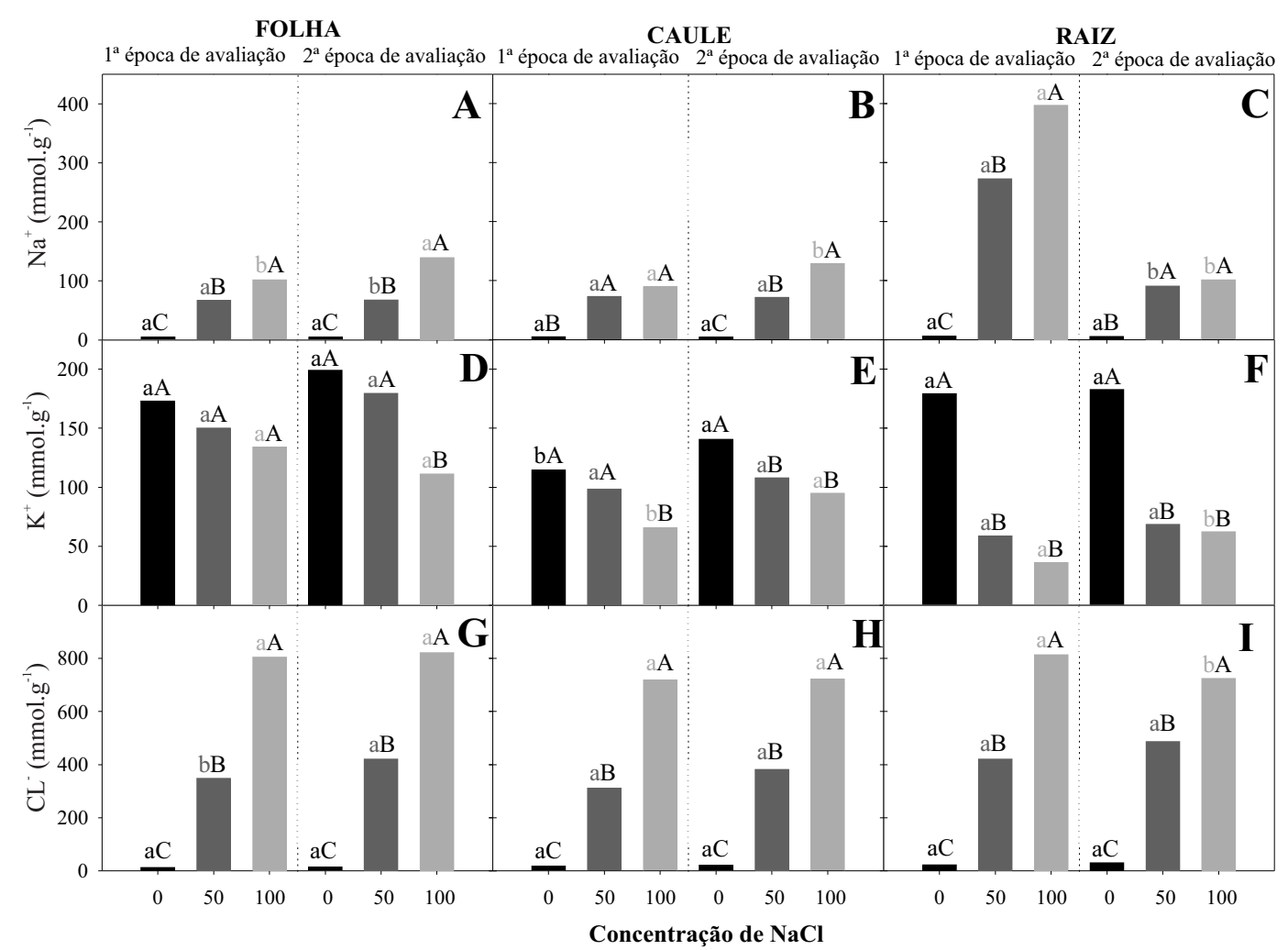

Figura 5 - Teores de sódio $\left(\mathrm{Na}^{+}\right)$, potássio $\left(\mathrm{K}^{+}\right)$e cloreto $\left(\mathrm{Cl}^{-}\right)$em folhas (A, D e G, respectivamente), caules (B, E e H, respectivamente) e raízes (C, F e I, respectivamente) em mudas de jatobá (Hymenaea courbaril L.) cultivadas em três níveis de salinidade, em duas épocas de avaliação. Letras maiúsculas comparam os tratamentos salinos em cada época de avaliação, e letras minúsculas pretas, cinza-escuras e cinza-claras comparam as plantas do tratamento-controle, $50 \mathrm{mM}$ e $100 \mathrm{mM}$ de NaCl , respectivamente. Letras iguais não diferem entre si, pelo teste de Tukey a $5 \%$. $1^{\text {a }}$ época de avaliação: constatação do fechamento estomático; e $2^{\mathrm{a}}$ época de avaliação: após a verificação da abertura estomática das plantas submetidas à salinidade.

Figure 5 - Levels of Sodium $\left(\mathrm{Na}^{+}\right)$, Potassium $\left(\mathrm{K}^{+}\right)$and Chloride $\left(\mathrm{Cl}^{-}\right)$in leaves $(A, D$ and G respectively), stems (B, E and $H$, respectively) and roots (C, $F$ and I respectively) in jatoba (Hymenaea courbaril L.) seedlings grown in three salinity levels in two evaluation periods. Capital letters compare the saline treatments in each timing and lowercase letters black, dark gray and light gray compare the control plants, $50 \mathrm{mM}$ and $100 \mathrm{mM} \mathrm{NaCl}$, respectively. Same letter do not differ by Tukey test at 5\%. 1st time evaluation: Finding the stomatal closure; and 2nd time evaluation: after verification of stomatal opening of plants subjected to salinity.

Estresses abióticos como o hídrico e o salino desencadeiam um conjunto de alterações bioquímicas, entre elas a elevação da concentração celular de aminoácidos solúveis totais. Esse comportamento pode estar associado ao ajustamento osmótico dos tecidos vegetais (SUBBARAO, 2000; BELTRÃO; OLIVEIRA, 2007), sendo esse ajuste, por sua vez, realizado por algumas plantas como tentativa de manter o potencial hídrico e a turgescência de suas células, próximas ao nível adequado.

A elevação nos teores de prolina observada neste trabalho ratifica o importante papel osmorregulador dessa substância, uma vez que vários relatos científicos indicam que plantas que acumulam esse aminoácido apresentam maior capacidade de tolerar estresses ambientais (SILVA et al., 2008; 2010; ESTEVES; SUZUKI, 2008; LARCHER, 2004; TURKAN, 2011). Maia et al. (2007) afirmaram que, em condições semelhantes de estresse, as plantas mais tolerantes sintetizam maior quantidade de prolina quando comparadas com plantas sensíveis, atuando como importante indicador de tolerância. De maneira geral, pode-se inferir que os distúrbios metabólicos apresentados pelas plantas submetidas ao estresse salino severo são atribuídos 
à ação iônica desencadeada pelo acúmulo de $\mathrm{NaCl}$. Comparando os teores de $\mathrm{Na}^{+} \mathrm{e} \mathrm{K}^{+}$, observou-se que o acúmulo do $\mathrm{Na}^{+}$promoveu diminuição dos teores de $\mathrm{K}^{+}$. Tal fato é resultante da competição pelos sítios ativos dos carreadores (BLUMWALD, 2000; TESTER; DAVENPORT, 2003), uma vez que o acúmulo de $\mathrm{Na}^{+}$ promove a interrupção da ação do $\mathrm{K}^{+}$como cofator enzimático, comprometendo vários processos metabólicos essenciais à planta (TESTER; DAVENPORT, 2003). Outro fato que merece ser destacado é que esse acúmulo ocorreu concomitantemente à elevação dos teores de solutos orgânicos, como resposta ao ajustamento osmótico e à manutenção da turgescência celular.

Corroborando os resultados obtidos neste estudo, Cunha (2009), trabalhando com mudas de pinhão-manso submetidas à salinidade, também verificou a elevação dos teores de $\mathrm{Na}^{+}$e $\mathrm{Cl}^{-}$em detrimento dos teores de $\mathrm{K}^{+}$. Essa autora atribuiu esse fato à ausência de mecanismos de extrusão da espécie em questão, não havendo mecanismo de impedimento da ação desses sais no metabolismo do vegetal.

Por fim, os resultados deste estudo sugerem que as plantas de jatobá se ajustaram osmoticamente, uma vez que os referidos acúmulos de substâncias, principalmente carboidratos, proteínas, aminoácidos e prolina nas folhas, promoveram a elevação da turgescência foliar, comprovado pelos elevados valores de TRA apresentados pelo tratamento $100 \mathrm{mM} \mathrm{de} \mathrm{NaCl}$, indicando que a manutenção do status hídrico das plantas, proveniente da osmorregulação, promoveu a estabilização das trocas gasosas, mesmo após a submissão à salinidade.

\section{CONCLUSÕES}

Após a exposição à salinidade, as mudas de jatobá se ajustaram osmoticamente, uma vez que acumularam solutos orgânicos que promoveram a elevação da turgescência foliar, resultando na recuperação das trocas gasosas, mesmo após a submissão ao estresse salino severo $(100 \mathrm{mM})$.

Recomendam-se as variáveis relacionadas às trocas gasosas (fotossíntese, transpiração, condutância estomática e eficiência do uso da água), os solutos orgânicos (prolina na raiz) e, principalmente, os solutos inorgânicos (teores de cloreto, sódio e potássio nas folhas, caules e raízes), para a caracterização do estado de tolerância de mudas de jatobá à salinidade.
Mudas de jatobá podem ser produzidas em níveis salinos de até $50 \mathrm{mM}$ de $\mathrm{NaCl}$, bem como empregadas ou utilizadas em programas de reflorestamento de áreas degradadas pela ação da salinidade, haja vista que elas são capazes de tolerar níveis moderados desse fator, sem comprometer seu desenvolvimento em ambiente controlado.

\section{REFERÊNCIAS}

AKÇA, Y.; SAMSUNLU, E. The effect of salt stress on growth, chlorophyll content, proline and nutrient accumulation, and $\mathrm{K} / \mathrm{Na}$ ratio in Walnut. Pakistan Journal of Botany, v.44, n.5, p.1513-1520, 2012.

AMORIM, A.V.; GOMES FILHO, E.; BEZERRA, M.A.; PRISCO, J.T.; LACERDA, C.F. Respostas fisiológicas de plantas adultas de cajueiro anão precoce à salinidade. Revista Ciência Agronômica, v.41, n.1, p.113-121, 2010.

BATES, L. S; WALDREN, R. P.; TEARE, I. D. Rapid determination of free proline for waterstress studies. Plant Soil, v. 39, p.205-207, 1973.

BELTRÃO, N.E.M.; OLIVEIRA, M.I.P. Biossíntese e degradação de lipídios, carboidratos e proteínas em oleaginosas. Campina Grande: Embrapa Algodão, 2007. 61p. (Documentos, 178)

BLUMWALD, E. Sodium transport and salt tolerance in plant cells. Current Opinion of Cell Biology, v.12, p.76-112, 2000.

BRADFORD, M.M. A rapid and sensitive method for the quantitation of microgram quantitues of protein utilizing the of protein-dye binding.

Analitycal Biochemistry, v.72, p.248-254, 1976.

CHAVES, M.M.; FLEXAS, J.; PINHEIRO, C. Photosynthesis under drought and salt stress: regulation mechanisms from whole plant to cell. Annals of Botany, v. 103, p.551-560, 2009.

CUNHA, P.C. Aspectos fisiológicos e bioquímicos de Jatropha curcas cultivada sob estresse salino. 2009. $60 \mathrm{f}$. Dissertação (Mestrado em Botânica) Universidade Federal Rural de Pernambuco, Recife, 2009.

Revista Árvore, Viçosa-MG, v.39, n.4, p.641-653, 2015 
DUBOIS, M.; GILLES, K.A.; HAMILTON, J.K.; REBERS, P.A. Colorimetric method for determination of sugars and related substances. Analytical Chemistry, v.28, n.3, p.350-356, 1956.

ESTEVES, B.S.; SUZUKI, M.S. Efeito da salinidade sobre as plantas. Oecologia Brasiliensis, v.12, n.4, p.662-679, 2008.

HOAGLAND, D.R.; ARNON, D.I. The waterculture method for growing plants without soil. Berkeley: California Agricultural Experiment Station, 1950. 32p. (Circular, 347).

HOLANDA, J.S.; AMORIM, J.R.A.; FERREIRA NETO, M.; HOLANDA, A.C. Qualidade da água para irrigação. In: GHEYI, H.R.; DIAS, N.S.; LACERDA, C.F. Manejo da salinidade na agricultura: Estudos básicos e aplicados. Fortaleza: Instituto Nacional de Ciência e Tecnologia em Salinidade, 2010. p.43-61.

LARCHER, W. Ecofisiologia vegetal. São Carlos: Rima, 2004. 531p.

LICHTENTHALER, H.K.; BUSCHMANN, C. Chlorophylls and carotenoids - Measurement and characterisation by UV-VIS. In: Current protocols in food analytical chemistry. Madison: John Wiley \& Sons, 2001. F4.3.1-F4.3.8,

LIU, C.; LIU, Y.; GUO, K.; FAN, D.; LI, G.; ZHENG, Y.; YU, L.; YANG, R. Effect of drought on pigments, osmotic adjustment and antioxidant enzymes in six woody plant species in habitats of southwestern China. Environmental and Experimental Botany, v.71, .n.1, , p.174-183, 2011.

LOBATO, A.K.S.; OLIVEIRA NETO, C.F.; COSTA, R.C.L.; SANTOS FILHO, B.G., CRUZ, F.J.R.; LAUGHINGHOUSE IV, H.D. Biochemical and physiological behavior of Vigna unguiculata (L.) Walp. under stress during the vegetative phase.

Asian Journal of Plant Sciences, v.7, n.1, p.44-49, 2008.

MAIA, P.S.P.; OLIVEIRA NETO, C.F.; CASTRO, D.S.; FREITAS, J.M.N.; LOBATO, A.K.S.; COSTA, R.C.L. Conteúdo relativo de água, teor de prolina e carboidratos solúveis totais em folhas de duas cultivares de milho submetidas a estresse hídrico. Revista Brasileira de Biociências, v.5, supl. 2, p.918-920, 2007.

Revista Árvore, Viçosa-MG, v.39, n.4, p.641-653, 2015
MALAVOLTA, E.; VITTI, G.C.; OLIVEIRA, S.A. Avaliação do estado nutricional das plantas - princípios e aplicações. Piracicaba: Associação Brasileira para a Pesquisa da Potassa e do Fosfato, 1989.

MATHEUS, M.T.; AMARAL, J.A.T.; SILVA, D.G.G.; NEVES, D.M.; PIZZOL, E.C.S.; SOUSA, F.C.; SANTI, G.C.; GUARIZ, H.R.; LIMA, K.A.; HOFFMANN, R.G. Sintomas de deficiência nutricional em Jatobá, Revista Científica Eletrônica de Engenharia Florestal, v.17, n.1, p.89-97, 2011.

MELO, M.G.G.; MENDONÇA, M.S.; MENDES, A.M.S. Análise morfológica de sementes, germinação e plântulas de jatobá (Hymenaea intermedia Ducke var. adenotricha (Ducke) Lee \& Lang.). Acta Amazonica, v.34, n.1, p.9-14, 2004.

MUNNS, R.; TESTER, M. Mechanisms of salinity tolerance. Annual Review of Plant Biology, v.59, p.651-681, 2008.

NASCIMENTO, H.H.C.; NOGUEIRA, R.J.M.C.; SILVA, E.C.; SILVA, M.A. Análise do crescimento de mudas de Jatobá (Hymenaea courbaril L.) em diferentes níveis de água do solo. Revista Árvore, v.35, n.3, p.617-626, 2011. (Edição Especial)

NOBEL, P.S. Physicochemical and environmental plant physiology. New York: Academic Press, 1999.

OLIVEIRA, A.B.; GOMES-FILHO, E.; ENÉASFILHO, J. O problema da salinidade na agricultura e as adaptações das plantas ao estresse salino. Enciclopédia Biosfera, v.6, n. 11, p. 1-16, 2010.

OSMOND, C.B.; BJÖRKMAN, O.; ANDERSON, J. Water movement and plant response to water stress. In: OSMOND, C.B.; BJÖRKMAN, O.; ANDERSON, J. Ecological studies.

Physiological process in plant ecology, towards a synthesis with Atriplex. Berlin: Springer-Verlag, 1980. p.480-547.

PARIDA, A.O.; DAS, A.B. Salt tolerance and salinity effects on plants: a review. 
Ecotoxicology and Environmental

Safety, v.60, n.3, p.324-349, 2005.

PIMENTEL, C. A relação da planta com a água. Seropédica: EDUR, 2004. 192p.

PINHEIRO, H.A.; SILVA, J.V.; ENDRES, L.; FERREIRA, V.M. Alterações na fotossíntese e nos teores de pigmentos cloroplastídicos em plântulas de mamona cultivadas sob condições de salinidade. In: CONGRESSO DA REDE BRASILEIRA DE TECNOLOGIA DE BIODIESEL, 1., 2006,. Brasília. Anais... Brasília: MCT/ ABIPTI, 2006. v.1. p.41-45.

RAHDARI, P.; HOSEINI, S.M. Salinity stress: a review. Technical Journal of Engineering and Applied Sciences, v.1, n.3, p.63-66, 2011.

RIBEIRO, M.R. Origem e classificação dos solos afetados por sais. In: GHEYI, H.R.; DIAS, N.S.; LACERDA, C.F. Manejo da salinidade na agricultura: estudos básicos e aplicados. Fortaleza: Instituto Nacional de Ciência e Tecnologia em Salinidade, 2010. p.11-19..

SCHOLANDER, P.F.; HAMMEL, H.T.; BRADSTREET, E.D.; HEMMINGSEN, E.A. Sap pressure in vascular plants. Science, v.148, n.3668, p.339-346, 1965.

SILVA, E.C.R.; NOGUEIRA, J.M.C.; ARAUJO, F.P.; AZEVEDO-NETO, A.D Physiological responses to salt stress in young umbu. Environmental and Experimental Botany, v.63, n.1, p.147-157, 2008.

SILVA, E.N.; RIBEIRO, R.V.; FERREIRA-SILVA, S.L.; VIÉGAS, R.A.; SILVEIRA, J.A.G.

Comparative effects of salinity and water stress on photosynthesis, water relations and growth of Jatropha curcas plants. Journal of Arid Environments, v.74, n.10, p.1130-1137, 2010.

SUBBARAO, G.V. Osmotic adjustment, water relations and carbohydrate remobilization in pigeonpea under water stress. Journal of Plant Physiology, v. 157, n.6, p.651-659, 2000.

TAIZ, L.; ZEIGER, E. Fisiologia vegetal. 5.ed. Porto Alegre: Artmed, 2013.918p.

TANAKA, A.; TANAKA, R. Chlorophyll metabolism. Current Opinion in Plant Biology, v.9, n.3, p.248-255, 2006.

TESTER, M.; DAVENPORT, R. Na+tolerance and $\mathrm{Na}+$ transport in higher plants. Annals of Botany, v.91, p. 503-527, 2003.

TURKAN, I. Plant responses to drought and salinity stress: developments in post-genomic Era. In: TURKAN, I. (Ed) Advances in botanical research. London: Elsevier, 2011. p.105-150. v. 57.

VIANELLO, R.L.; ALVES, A.R. Meteorologia básica e aplicações. Viçosa, MG: Imprensa Universitária, 1991. p.433-434.

WEATHERLEY, P.E. Studies in the water relations of the cotton plant. I- The field measurements of water deficits in leaves. New Phytologist, v.49, n.1, p.81-97, 1950.

YEMM, E.W.; COCKING, E.C. Determination of amino acids with ninhydrin. Analyst, v.80, p.209-213, 1955.

ZHU, J.K. Regulation of ion homeostasis under salt stress. Current Opinion in Plant Biology, v.6, n.2, p.441-445, 2003. 